\title{
Neuroendocrine Abnormalities Following Traumatic Brain Injury: An Important Contributor to Neuropsychiatric Sequelae
}

OPEN ACCESS

Edited by:

Lee E. Eiden,

National Institutes of Health

$(\mathrm{NIH})$, United States

Reviewed by:

Ben Nephew

Tufts University, United States Hirokazu Ohtaki,

Showa University, Japan

${ }^{*}$ Correspondence:

Amir M. Molaie

amir.molaie@tufts.edu

Specialty section: This article was submitted to Neuroendocrine Science, a section of the journal Frontiers in Endocrinology

Received: 05 February 2018 Accepted: 03 April 2018

Published: 25 April 2018

Citation:

Molaie AM and Maguire J (2018) Neuroendocrine Abnormalities

Following Traumatic Brain Injury: An Important Contributor to Neuropsychiatric Sequelae.

Front. Endocrinol. 9:176. doi: 10.3389/fendo.2018.00176

\author{
Amir M. Molaie ${ }^{1 *}$ and Jamie Maguire ${ }^{2}$ \\ ${ }^{1}$ Tufts University School of Medicine, Boston, MA, United States, ${ }^{2}$ Department of Neuroscience, Sackler School of Graduate \\ Biomedical Sciences, Boston, MA, United States
}

Neuropsychiatric symptoms following traumatic brain injury (TBI) are common and contribute negatively to TBI outcomes by reducing overall quality of life. The development of neurobehavioral sequelae, such as concentration deficits, depression, anxiety, fatigue, and loss of emotional well-being has historically been attributed to an ambiguous "post-concussive syndrome," considered secondary to frank structural injury and axonal damage. However, recent research suggests that neuroendocrine dysfunction, specifically hypopituitarism, plays an important role in the etiology of these symptoms. This post-head trauma hypopituitarism (PHTH) has been shown in the past two decades to be a clinically prevalent phenomenon, and given the parallels between neuropsychiatric symptoms associated with non-TBI-induced hypopituitarism and those following TBI, it is now acknowledged that PHTH is likely a substantial contributor to these impairments. The current paper seeks to provide an overview of hypothesized pathophysiological mechanisms underlying neuroendocrine abnormalities after TBI, and to emphasize the significance of this phenomenon in the development of the neurobehavioral problems frequently seen after head trauma.

Keywords: traumatic brain injury, hypopituitarism, anterior pituitary, neuropsychiatric symptoms, post-concussive syndrome

\section{INTRODUCTION}

\section{Neuropsychiatric Sequelae of Traumatic Brain Injury (TBI)}

Traumatic brain injury affects approximately 10 million people worldwide annually and 1.7 million in the U.S. alone (1-3). The most common TBIs occur secondary to motor vehicle trauma, and the incidence has been growing as low- and middle-income countries increase motor vehicle use, with a projected rise of $50 \%$ from 2002 to 2020 (4-6). Sports injuries are also frequent causes of TBI; in fact, almost 500,000 sports-related TBI emergency department visits were reported nationwide between 2006 and 2011 (7). In addition, more than 300,000 military service members have been diagnosed with combat-related TBI since 2000 (8).

A wide spectrum of neurologic sequelae of TBI has been described, ranging from cognitive problems to emotional and behavioral symptoms. Neuropsychiatric complaints in particular play a significant role in TBI morbidity (9). These include concentration problems, depression, anxiety, fatigue, and loss of emotional well-being, and occur in approximately $30 \%$ of brain injury patients (10-16). This constellation of neuropsychiatric symptoms has been recognized across all levels of 
TBI severity, and has historically been loosely classified as part of a general post-concussive syndrome, or PCS, that was thought to be due to brain injury per se (17). According to the World Health Organization's International Classification of Diseases, PCS is defined as the presence of three or more of the following symptoms that must be present within the first month post-injury, including headache, dizziness, fatigue, irritability, insomnia, and concentration or memory difficulty (18). More long-term sequelae, such as major depression, alcohol abuse or dependence, panic disorder, or psychotic syndromes have also been noted after TBI, regardless of severity $(19,20)$.

The clinical relevance of these findings is becoming apparent as increasing numbers of patients with TBIs are surviving due to improved acute care, and therefore, are more commonly developing neuropsychiatric symptoms. Importantly, even as the lethality of weapons in the war zone has increased due to widespread use of improvised explosive devices, improvements in body armor have led to better survival rates of soldiers (21). Consequently, a higher proportion of wounded soldiers returns home with TBIs and subsequently develops various sequelae (22). The clear decrease in quality of life (QoL) in patients suffering from these symptoms has prompted a thorough investigation of the pathophysiology behind them, and has led to exciting new fronts regarding the possible mechanisms of these post-TBI complications. The current paper will highlight hypothesized pathophysiological mechanisms of one likely culprit of neurobehavioral symptoms: pituitary function abnormalities associated with head trauma.

\section{The Pituitary Gland}

The pituitary sits in a pocket of bone called the sella turcica of the sphenoid bone and is covered by a layer of dura mater called the diaphragm sella. A small organ, approximately the size of a pea and normally weighing less than a gram, the pituitary gland consists of distinct sections: the pars distalis, pars tuberalis, and pars intermedia [the three of which compose the anterior pituitary (AP)], as well as the pars nervosa (the posterior pituitary). The pars distalis describes the bulk of the AP, while the tuberalis designates the sheath that joins the infundibular stalk. The pars intermedia, situated between the pars distalis and nervosa, is responsible for only a minor portion of pituitary function. The AP releases growth hormone $(\mathrm{GH})$, adrenocorticotropic hormone $(\mathrm{ACTH})$, gonadotropins, thyroid-stimulating hormone (TSH), and prolactin after being directed to do so by specific hypothalamic activating hormones that arrive to the AP via the hypophysealportal capillary network (with the exception of prolactin, which is primarily released through the removal of tonic inhibition by dopamine). The posterior pituitary, by contrast, secretes antidiuretic hormone $(\mathrm{ADH})$ and oxytocin after receiving neural input from the hypothalamic tract (23).

\section{Neuroendocrine Dysfunction Following TBI}

There is increasing evidence that pituitary disruption is a common consequence of TBI, as well as a likely contributor to PCS-like symptoms. Posterior pituitary abnormalities, namely of $\mathrm{ADH}$, such as in syndrome of inappropriate secretion of $\mathrm{ADH}$ or diabetes insipidus, are already well-recognized consequences of TBI, given their clinically apparent presentations of fluid balance dysregulation in the body. Clinicians have historically missed AP abnormalities following head injury, however, likely as a result of their more variable clinical presentations, as well as the subtlety of their symptoms, which can lead to underreporting by patients.

The first case of post-head trauma hypopituitarism (PHTH) was reported in 1918 (24), though the syndrome did not garner significant attention until the turn of this century. Since then, a large body of research has demonstrated the importance of PHTH (25-33), even from minor trauma (34), such as sport-related concussions (35-37) and blast-related mild TBIs in veterans (38-40). Kelly and colleagues were the first group to systematically evaluate the prevalence of hypopituitarism long-term after TBI (25). Examining 22 patients with mild, moderate, and severe TBIs at least 3 months out from a head injury (median of 26 months), the authors found that $36.4 \%$ of patients had subnormal responses in at least one hormonal axis. The most substantial impairment found was that of $\mathrm{GH}$, with $18.2 \%$ of patients provoking an inadequate response to the insulin tolerance test (ITT). Regarding other hormones, one patient presented with corticotroph response impairment and one with gonadotropin deficiency.

Later, a notable large-scale study designed by Agha et al. examined 102 patients at least 6 months post-injury (median of 19 months) (27). The authors used more stringent measures for defining hypopituitarism by reporting patients as $\mathrm{GH}$ deficient only if they failed in both the glucagon stimulation test and the ITT, thereby confirming clinical deficiency. Despite the stricter guidelines, GH deficiency (GHD) was still found in $10.7 \%$ of patients and severe GHD was indicated in $8.8 \%$, as defined by the arginine $+\mathrm{GH}$ releasing hormone $(\mathrm{GHRH})$ test. Deficiency in the corticotropic axis was likewise defined using two provocative tests rendering a $12.7 \%$ prevalence of ACTH deficiency. Moreover, $11.8 \%$ had evidence of gonadotropin deficiency, though this was also significantly correlated with age.

More recently, Abadi and others conducted a prospective study of 75 patients with moderate TBI, assessing pituitary function 3 and 6 months post-injury (32). Overall, $48 \%$ of patients demonstrated at least one AP abnormality; the most prevalent was insulin-like growth factor 1 (IGF-1) insufficiency, found in $24 \%$ of patients after 3 months. Circulating levels of IGF-1, which is produced by the liver per GH stimulation, can be used to indicate anomalies in somatotroph function. It is important to mention that low IGF-1 concentration is reasonably specific for GHD; however, its diagnostic sensitivity is low and, therefore, normal or even elevated levels cannot exclude GHD (41). Gonadotropin and cortisol deficiencies occurred in 16 and $13.3 \%$ of patients, respectively, at the 3-month assessment. Notably, these percentages did decrease at the 6-month timepoint.

Overall, the most frequent abnormalities reported are GHD, ACTH insufficiency, and gonadotropin deficiency (29, 32, 42-44). Yet, taken together, results from prospective studies on both short- and long-term endocrinopathies are quite varied in terms of purported incidence, ranging generally from 10 to $58 \%$ $(38,45,46)$. Therefore, the literature is still currently divided on the clinical pertinence of PHTH, and while some claim that it represents an under-diagnosed phenomenon, others argue it 
does not occur as commonly as proponents propose $(47,48)$. It has been suggested that because many studies on PHTH did not perform secondary confirmatory testing, the reported prevalence of pituitary deficiencies is inflated. Furthermore, it is important to acknowledge that using various tests, assays, and cutoffs has a significant effect on the purported deficiency rates $(49,50)$. For instance, Klose et al. measured a prevalence of GHD in as low as $1 \%$ of TBI patients depending on the guidelines used (49). In a very recent opinion article, Klose and Feldt-Rasmussen propose that the high percentages reported in the literature are secondary to short-term studies of favorably selected patient groups (48).

Despite disagreement on the exact prevalence of $\mathrm{PHTH}$, most studies and reviews demonstrate that hormone disruptions do occur in some TBI-affected individuals, as outlined above. In fact, recent recommendations offered by Tan et al. propose that TBI patients should obtain pituitary screening at 3-6 months post-injury if they underwent prolonged hospital stays, or show symptoms consistent with pituitary dysfunction (44). Interested readers can refer to thorough reviews by Tanriverdi and colleagues (43) and Tan et al. (44), which summarize studies done to date on the prevalence of chronic PHTH, discuss the frequency of various deficiencies, and comment on the methods used in experiments.

Interestingly, in patients with chronic hypopituitary issues not secondary to head trauma, similar complaints of fatigue, depression, anxiety, and loss of emotional well-being also arise (51). GHD in particular is associated with diminished psychological health and decreased QoL in adults, and since about 30 years ago has been designated as its own specific clinical syndrome (52). Research has revealed significant decreases in energy and emotional lability, heightened sense of social isolation, greater difficulties with sexual relationships, decreased QoL, and greater psychological distress in untreated versus treated GHD (53-55). Furthermore, it has been repeatedly demonstrated that post-TBI GHD is similarly associated with impaired motivation, depression, and decreased QoL, with no convincing role of trauma severity (40, 56-58). Therefore, it comes as no surprise that these same symptoms after head trauma that were once regarded simply under the umbrella of post-concussive syndrome are being reconsidered in the context of $\mathrm{PHTH}$ and specifically post-TBI GHD. Moreover, many symptoms of post-traumatic stress disorder (PTSD) overlap with those of TBI, and questions have arisen whether neuroendocrine pathologies may contribute to PTSD in the setting of head trauma $(59,60)$. Although it is extremely complicated to parse out which symptoms attributed to PTSD may be specifically linked to brain injury as such, knowing what symptoms may be due to neuroendocrine abnormalities is being given special attention (61).

\section{PATHOPHYSIOLOGY OF TBI AND PHTH}

\section{The Typical Neuroendocrine Response of the Pituitary to Stress or Injury}

In examining endocrinopathies after TBI, it is important to first consider the standard stress response to injury that affects cortisol and other endocrine hormones. In the acute phase of the response following trauma (accepted as within the first $24 \mathrm{~h}$ post-injury) and subacutely (several days after injury), a predictable neuroendocrine sequence occurs that is well-documented (62). There is a biphasic pattern of acute metabolic changes described as an "ebb" and a "flow." First, a sympathoadrenal storm takes place in the first few hours post-injury which characterizes the "ebb" phase. This consists of a decrease in overall energy expenditure as the body and brain attempt to protect homeostasis by altering normal tissue perfusion. Next, a "flow" phase takes over, during which catabolic processes provide substrates for trauma repair (63). Overall, the acute and subacute periods following injury exhibit elevated AP function. GH is known to participate in widespread signaling that contributes to cellular recovery after trauma, and augmented ACTH release promotes hypercortisolism in an effort to metabolically support the body while healing takes place, protect against excessive immune responses, and recover hemodynamic status $(64,65)$.

Until recently, it was assumed that the cellular and metabolic events that take place during the acute and subacute phases continue throughout the course of long-term illness. However, findings of late suggest that the neuroendocrine response to injury changes in prolonged stress $(66,67)$. Van den Berghe et al. reported that during protracted critical illness, overall pituitary secretions are actually diminished: pulsatile release of ACTH, $\mathrm{GH}, \mathrm{TSH}$, and prolactin decrease (although notably hypercortisolemia continues via non-ACTH-mediated pathways) $(65,68)$. It remains an ongoing controversy whether these AP changes represent an adaptation to benefit survival or signify a dysfunction during protracted states of particularly critical illnesses, but current thought views chronic alterations as detrimental, and in fact something to therapeutically intervene in (65).

\section{The Neuroendocrine Response to TBI}

The neuroendocrine and metabolic response to brain injury is thought to proceed similarly to extracerebral injury in the acute and subacute phases $(69,70)$. One must, therefore, consider based on Van den Berghe's findings that chronic hypopituitarism observed after TBI may simply represent a response similar to that observed in protracted illness, rather than a unique pathologic phenomenon. However, certain points argue that chronic PHTH should instead be considered a distinct pathology. For example, the hypopituitarism Van der Berghe reported appeared to have a hypothalamic rather than pituitary origin, which differs from the likely sources of PHTH, as will be discussed below. Furthermore, most PHTH patients present with one or few AP abnormalities, whereas the changes seen in chronic critical illness take place on a broader level.

Recent experiments by Taylor and colleagues argue for TBIspecific mechanisms that modify the standard stress response to create PHTH. They showed that moderate TBI in adult male rats leads to altered glucocorticoid receptor and GABA receptor signaling which produces increased negative feedback control of the HPA axis, causing subsequent long-term dysregulation of the neuroendocrine stress response (71-73). This may be a significant key in explaining diminished ACTH seen after TBI. Notably, as will be discussed below, a similar sensitization to negative feedback of the HPA axis has been shown to occur in 
patients with PTSD, offering a clue to how psychiatric symptoms might manifest from neuroendocrine dysfunction (61).

\section{Mechanisms of Neuroendocrine Disruption After TBI}

The specific pathophysiological changes that induce $\mathrm{PHTH}$ remain elusive. However, in addition to the reports by Taylor and colleagues documenting TBI-related damage to the stress response pathway (71-73), several other hypotheses have been offered that are backed by experimental data, including (i) vulnerability of the AP gland to damage and (ii) immune system involvement.

\section{AP Damage}

The pathophysiology of posttraumatic pituitary damage is complex, involving primary focal insults as well as secondary damage due to edema, hemorrhage, hypotension, and hypoxia (11). Swelling of the pituitary compresses the gland, as it sits within an inflexible bony compartment, roofed over with the diaphragm sella (74). Shearing forces from trauma can directly injure the pituitary gland itself or the infundibulum that connects it to the hypothalamus. Skull base and sella turcica fractures can produce focal damage and have been reported in cases of PHTH (75), although it should be acknowledged that most studies and reports of PHTH have been in patients without sellar fractures. Damage to the pituitary stalk could affect the pituitary hormone-producing chromophils in the pars tuberalis, namely gonadotroph, corticotroph, and thyrotroph cells, which produce gonadotropins, ACTH, and TSH, respectively $(76,77)$. The association of post-TBI hyperprolactinemia to $\mathrm{PHTH}$ is also thought to be secondary to pituitary stalk compression, leading to withdrawal of dopaminergic inhibitory control (78). In line with this, it is possible that structural damage to the infundibulum could also produce other post-TBI pituitary deficiencies by removing hypothalamic input. Direct damage to the hypothalamus, on the other hand, is not typically seen as a consistent or major pathological factor leading to chronic PHTH. However, a recent experiment using a model of intracranial hypertension did show increased apoptosis throughout the HPA axis, including the hypothalamus, pituitary, and hippocampus (79). Other pathologies related to the hypothalamus have been suggested: a recent study by Tümer et al. found heightened expression of oxidative stress mediators in the hypothalamus after blast-induced trauma in rats (80). PostTBI autoimmunity directed at the hypothalamus has also been discovered (81) and will be explored shortly.

Ischemic injury is hypothesized to play a considerable role in $\mathrm{PHTH}$ pathology given the vascular vulnerability of the AP gland. The concept of AP sensitivity to ischemia was proposed many years ago (82) and has been supported since by anatomical, clinical, and autopsy evidence. Structurally, the anterior lobe of the pituitary derives its blood supply primarily from hypophyseal-portal circulation; namely, from the long portal vessels, which branch from the superior hypophyseal artery after it forms a capillary plexus in the median eminence. Running along the infundibulum to the AP, these vessels are predisposed to damage from mechanical forces, hypertension, hypotension, and edema $(83,84)$.
Regions of the AP, either located peripherally (and, therefore, distal to the main blood supply) or in areas not subject to sufficient collateral flow seem to be the most affected in PHTH. The long portal veins are generally recognized to supply $70-90 \%$ of the anterior lobe parenchyma, predominantly in the anterior central regions. By contrast, the short portal vessels, which branch off the inferior hypophyseal artery, supply the posterior pituitary as well as $10-30 \%$ of the adjacent AP posteriorly $(83,85)$. Somatotrophs, which produce $\mathrm{GH}$ and are the most abundant chromophil cells in the pituitary, tend to localize more in the lateral and peripheral regions (although they also scatter medially), which might make them particularly sensitive to ischemia due to their downstream position relative to the long portal vessels $(86,87)$. In cases of Sheehan's syndrome, wherein postpartum hemorrhage causes ischemic necrosis of the pituitary, GH deficiency is also one of the earliest hormones lost (88).

After trauma, a small posterior area of the AP and the outermost layer immediately deep to the capsule tend to survive, likely secondary to collateral from the short portal vessels and a variable amount of extraportal end-arterial circulation, respectively (82, 83). Corticotropic cells, on the other hand, are clustered centrally in the AP and may not have such dual supply, and can, therefore, be susceptible to necrosis in cases of ischemic damage from TBI (77). Corticotrophs can also be found in the lateral wings of the AP, in the pars intermedia, and in the pars tuberalis. Gonadotrophs lie diffusely throughout the pars distalis and constitute the majority of the pars tuberalis $(77,87)$.

Some authors emphasize an anterolateral distribution of the vulnerable long portal vessels and designate an anteromedial distribution of the short portal vessels into the AP; this might explain the frequent damage to the lateral somatotrophs, as well as the infrequency of TSH deficiency, given that thyrotrophs cluster medially $(11,23)$. However, this distinction of lateral versus medial distribution is not firmly established in the field.

Many autopsy case reports also support the significance of pituitary vascular vulnerability in TBI and PHTH. Studies decades ago by Ceballos (89) and Kornblum and Fisher (90) of over 200 TBI subjects revealed AP necrosis in about $22 \%$ of patients. More recently, it was found by Benvenga et al. in a review of cases that approximately $1 / 3$ of TBI fatalities demonstrated pituitary gland necrosis (91). Another recent histological study revealed acute adenohypophyseal infarcts in $43 \%$ of specimens (92).

Part of the difficulty of supporting this hypothesis in the past was the lack of systematic imaging studies that correlated PHTH with any focal pituitary pathological abnormalities. In their aforementioned review published in 2000, Benvenga and colleagues noted CT or MRI lesions of the pituitary or hypothalamus in all but $6.6 \%$ of PHTH patients (91). Since then, focused imaging studies have confirmed that pathologic vascular changes of the pituitary take place both in the acute and chronic phase after brain injury $(74,93)$. Maiya et al. found MRI irregularities consistent with edema, hemorrhage, or infarction in $30 \%$ of TBI patients (74). Furthermore, when directly assessing the relationship between PHTH and MRI findings, Schneider and colleagues observed a higher frequency of chronic pituitary imaging abnormalities in TBI patients with hypopituitarism compared to TBI patients without hypopituitarism (93). They described a pattern 
of pituitary volume reduction as well as signal inhomogeneities interpreted to represent hemorrhage, necrosis, or fibrosis. The loss of pituitary volume seen in the sella can be attributed to the combined effects of increased intracranial pressure and pituitary necrosis (94). Recently, a prospective study by Zheng et al. using MRI with diffusion-weighted imaging showed that compared to controls, TBI patients displayed decreased pituitary tissue water diffusivity, recognized as a marker for microstructural damage, such as white matter lesions (95). Further, they found that the TBI patients who demonstrated hypopituitarism exhibited lower values for water diffusivity than those without hypopituitarism.

Several studies in animal models of closed head injury have also confirmed pituitary damage with neuroendocrine dysfunction secondary to TBI. For example, Greco et al. demonstrated GH/IGF-1 axis disruptions and pituitary vascular damage in rats after repeated TBIs (96). Damage in the HPA axis upstream of the pituitary gland has also been found; for instance, neuronal apoptosis in the hippocampi of rats after head trauma was shown to be associated with decreased levels of IGF-1 (97). Furthermore, an intriguing mechanism established of late is the disruption of tanycyte function after cortical contusion injury (CCI) in mice (98). Tanycytes are specialized glia lining the third ventricle that mediate the crossing of blood-borne substances into the brain (99). The authors conclude that rupture of the tanycyte barrier likely contributed to the diminished GH levels seen in mice that underwent CCI.

\section{Immune System Involvement}

Several other hypotheses regarding the pathology of PHTH development have also been proposed and have empirical support. One such example relates to genetic differences in $\mathrm{PHTH}$ predisposition, namely through polymorphisms in apolipoprotein E (APO E) (38). APO E is a lipoprotein manufactured in the central nervous system, and is produced in greater quantities following injury. Studies have shown APO E inhibits the neuroinflammatory cascade after injury, with the APO E3 isoform doing so with greater effectiveness than APO E4 (100). In a study of 93 TBI patients, those with APO E3/E3 genotypes were significantly less likely to suffer from PHTH (101). Therefore, one might speculate that secondary insults in the form of neuroinflammation and cytokines may be important in pituitary pathology after TBI. Animal studies have also suggested a role of inflammation in PHTH. Kasturi and colleagues demonstrated increased expression of inflammatory mediators, such as interleukin IL-1 $\beta$ and glial fibrillary acidic protein (a marker of astrogliosis) in the cerebral cortex, hypothalamus, and AP of rats after CCI (102).

Another characteristic of inflammation also warrants attention: autoimmunity, and particularly the role of anti-hypothalamic antibodies (AHAs) and antipituitary antibodies (APAs) (81). The importance of autoimmunity in PHTH was first proposed in 2008 by Tanriverdi and colleagues after detecting APAs in $44.8 \%$ of TBI patients 3 years post-injury (103). No APAs were found in controls. They discovered that APA-positive individuals were at significantly higher risk for $\mathrm{PHTH}$, and high APA titers correlated with lower $\mathrm{GH}$ response to stimulation by GHRH + GHRP-6 (GH releasing peptide). A subsequent 5-year prospective study of 25 of the 29 patients in this same TBI group revealed that $60 \%$ of patients had AHAs and $48 \%$ had APAs, and of those proportions, individuals who tested strongly positive for these antibodies remained more likely to have PHTH (104). This pathophysiological finding was also tested in individuals who sustained chronic/ repetitive mild TBIs. Antibodies to the hypothalamus or pituitary were present in 21.3 and $22.9 \%$ of boxers, respectively, but again in no controls (105). AHA positivity was significantly associated with hypopituitarism; however, APA positivity in this instance was not. Altogether, these results lend credence to the importance of neuroinflammation in the pathogenesis of PHTH.

\section{Neural Circuitry Abnormalities and Post- TBI Neurobehavioral Symptoms}

While PHTH is likely an important contributor to neuropsychiatric symptoms of TBI, other pathophysiological causes have also been hypothesized to play a role. Neuronal axons have been shown to be particularly susceptible to damage from TBI (106). In fact, diffuse axonal injury (DAI) due to inertial forces of rapid head acceleration/deceleration or rotation encompass arguably the most common and important pathologies, even after mild TBI $(78,107)$. Cytoskeletal breakdown and disruptions in axonal transport cause axonal swelling and disconnection from targets, leading to neuronal degeneration (108).

Until recently, assessing DAI in vivo has been a challenge, as conventional CT and MRI scanning were not able to detect such microscopic and pervasive changes. However, advances in the form of diffusion tensor imaging have furnished the potential to detect acute axonal changes indicative of DAI by measuring anisotropic movement of water molecules, and thereby characterizing white matter microstructural changes (109). In addition, resting-state functional MRI now affords researchers the ability to study the connectivity component of neural networks through measurement of the blood oxygenation level-dependent signal (110). These developments in neuroimaging have led to the understanding that structural compromise of neurons in DAI likely contributes significantly to functional disruptions of cognition by interfering with proper connections within certain neural circuits. The default mode network (DMN), for instance, is a functional circuit that describes the thoroughly investigated "resting state network." The DMN is active during passive mental activities when the brain is not partaking in any specific goaldirected tasks requiring attention (111). Numerous studies have found decreased connectivity in this circuit following TBI, either from damage to important relay points (i.e., nodes) within the network or due to axonal injury between nodes (110). In addition, further abnormalities in the DMN after TBI were demonstrated specifically during attention-requiring tasks. Bonnelle et al. showed that moderate to severe TBI patients demonstrated abnormalities in $\mathrm{DMN}$ deactivation during a sustained attention task that were directly predicted by the magnitude of white matter damage within Salience Network tracts (a circuit which generally becomes active when engaging in tasks that solicit attention) (112). This is significant, as it was previously shown that a similar failure to inhibit the DMN correlates directly with lapses in attention during concentration-requiring tasks, a common sequela of TBI (113). 
Given the circuitry changes seen in patients with TBI-induced concentration deficits, one might infer that interference with neural circuits is likely a significant contributor in provoking other neuropsychiatric symptoms as well. Consistent with this hypothesis, Zhou and others found that mild TBI patients demonstrated particular DMN dysfunction-specifically regarding connectivity changes around the medial prefrontal cortex (MPFC) that were related to patient reports of depression, anxiety, and other PCS symptoms (114). However, the authors note that these DMN abnormalities are different from those seen in clinical anxiety disorder and depression. But they suggest that over the long term, the MPFC alterations seen after TBI could lead to similar persistent psychological problems.

Damage to certain frontal-subcortical circuits, which play important roles in cognition and social considerations, have also been predicted to cause disruptions in behavior after injury to pertinent nodal regions $(115,116)$. These circuits include (1) a network arising in the dorsolateral prefrontal cortex regulating executive functions (i.e., decision making, problem solving, working memory), (2) a network based in the orbitofrontal cortex, which modulates intuitive social reactions and comportment, and (3) a third originating in the anterior cingulate cortex that modulates motivation-related behavior. Animal studies have also supported the pertinence of prefrontal cortex remodeling in the pathogenesis of TBI (117). Overall, disturbances in functional neural circuits are being investigated thoroughly for answers regarding cognitive and neurobehavioral abnormalities after TBI, and may in fact overlap with disturbances in pituitary function. For instance, upstream circuits regulating neuroendocrine pathways, such as those traversing medial temporal structures like the hippocampus or amygdala-which are commonly injured in TBI-may result in dysfunction of the HPA axis due to impaired regulation (116).

Damage to similar brain areas as discussed here has also been implicated in the pathogenesis of PTSD (118). The pathophysiological basis of PTSD, however, is incredibly diverse and quite complex.

\section{THE MYSTERIOUS CASE OF PTSD}

While PTSD is not a frank sequela of TBI, PTSD and TBI are often comorbid and share many overlapping symptoms, such as fatigue, irritability, poor sleep, and concentration deficits (119, 120). The fact that they often coexist brings up the question of whether PTSD and TBI share a common pathological mechanism. At present, PTSD is recognized as a phenomenon related to a psychological insult bringing about structural or cellular changes, as brain injury is clearly not required for PTSD development. Therefore, even in patients with PTSD and TBI, physiologic damage from trauma is not seen as the inciting factor leading to the reorganization of brain activity patterns. Rather, the memory of the event and the associated psychic trauma is considered the etiology. It has even been proposed that amnesia associated with TBI might actually protect against PTSD, with a prospective study finding higher rates of PTSD among TBI patients who remembered the traumatic incident (121). Pharmacologic studies corroborate this notion: drug therapies aimed at inhibiting consolidation of emotionally disturbing memories prevent their subsequent recall $(122,123)$. In PTSD, propanolol given in conjunction with traumatic memory reactivation, or "re-consolidation," has shown promise in decreasing symptoms $(124,125)$. However, the effect of TBI on the development of PTSD is still in dispute. It has been postulated that implicit processing of traumatic experiences takes place in spite of amnesia for the event, and that TBI does not reduce the frequency of PTSD (126). A military survey of soldiers returning from Iraq reported $44 \%$ of troops who had sustained mild TBIs with loss of consciousness screened positive for PTSD as compared to $16 \%$ who sustained only bodily injury (127). Additionally, a very recent study of veterans returning from dangerous posts in Iraq or Afghanistan found significant main effects of mild TBI on self-report questionnaires measuring PTSD symptoms (60). From an experimental angle, an animal study by Elder and others found that blast exposure causing mild TBI in anesthetized mice provoked PTSD-related traits, such as increased startle response (i.e., anxiety), enhanced contextual fear response, altered response in a predator scent assay, and increased expression of a protein involved in the fear response, suggesting that frank structural injury from the blast may have been the cause of the symptoms rather than memory of the event (120).

Currently, one of the predominant theories of PTSD comes from a neuroanatomical perspective that highlights the role of hyper-responsiveness of the amygdala to stimuli secondary to ineffective "top-down" processing by the prefrontal cortex (78). More recent theories have argued that disturbances between certain functional brain circuits, such as between the salience and DMNs, are partly to blame (128). Interestingly, these same neural circuitry abnormalities are seen in both TBI and PTSD (78). Overall, however, the vast heterogeneity of pathophysiology associated with PTSD poses a major challenge in making comparisons to TBI.

It is unclear to what degree PHTH might, if at all, contribute to the development of PTSD. The potential role of cortisol in PTSD was initially investigated intensively due to its significance in the stress pathway. It was assumed that PTSD patients would display elevated levels given the function of cortisol in the stress response. But numerous reports of PTSD patients with abnormally low corticosteroids challenged this assumption (61). Mason et al. were the first to demonstrate low cortisol levels in PTSD patients when comparing urinary free-cortisol levels between different psychiatric patient populations in the hospital (129). Many other studies followed; a notable study was performed by Resnick and colleagues, who studied cortisol levels within $51 \mathrm{~h}$ in victims of rape (130). They found that individuals with a history of previous assault displayed lower cortisol levels after a successive rape and had increased probability of developing PTSD. Related studies investigated the possible mechanisms behind this and have shown that PTSD patients have heightened sensitivity to glucocorticoid negative feedback and augmented negative feedback inhibition of the HPA axis as a whole (61). Recall, Taylor and colleagues proposed similar abnormalities in TBI (71-73). Additional research has given further credence to the notion that diminished cortisol response to stress/trauma may play a role in PTSD, but altogether the literature is substantially inconsistent. An abundance of studies have been conducted that yielded mixed 
results, finding decreased, increased, or unchanged basal levels of cortisol in PTSD patients and PTSD animal models, likely due to differences in the timing and type of trauma incurred (psychosocial, physical, acute, and chronic) (59). An excellent review by Zoladz and Diamond (61) delves into the conflicting literature regarding the neuroendocrine response and PTSD development. However, if low cortisol does correlate to likelihood of PTSD, one could imagine a role of PHTH in exacerbating or predisposing a person to developing this disorder. This is nonetheless speculative at this point. And yet, one aforementioned study of veterans did report intriguing results: using self-report questionnaires to investigate the relationship between TBI, overall hypopituitarism, and PTSD, the authors revealed a significant main effect of TBI-induced hypopituitarism on questionnaires assessing PTSD symptoms (60).

\section{CONCLUSION}

Neuropsychiatric symptoms after TBI are common and impair QoL of survivors. Hypotheses concerning the pathological roots of these sequelae have pointed to a number of causes, of which $\mathrm{PHTH}$, and particularly post-TBI GHD, is likely particularly important. Through pathophysiological pathways such as ischemic injury to the pituitary and immune-related mechanisms, head trauma frequently produces disruptions in AP function. As more prospective studies are done to ascertain the true prevalence of PHTH, the true contribution of these pathophysiological

\section{REFERENCES}

1. Mark Faul LX, Wald MM, Coronado VG. Traumatic Brain Injury in the United States: Emergency Department Visits, Hospitalizations and Deaths 2002-2006. Atlanta, GA: Centers for Disease Control and Prevention, National Center for Injury Prevention and Control (2010).

2. Blennow K, Brody DL, Kochanek PM, Levin H, McKee A, Ribbers GM, et al. Traumatic brain injuries. Nat Rev Dis Primers (2016) 2:16084. doi:10.1038/ nrdp. 2016.84

3. Morrissey K, Fairbrother H. Severe traumatic brain injury in children: an evidence-based review of emergency department management. Pediatr Emerg Med Pract (2016) 13(10):1-28.

4. Maas AI, Stocchetti N, Bullock R. Moderate and severe traumatic brain injury in adults. Lancet Neurol (2008) 7(8):728-41. doi:10.1016/ S1474-4422(08)70164-9

5. Lowenstein DH. Traumatic brain injury: a glimpse of order among the chaos? Ann Neurol (2009) 66(4):A7-8. doi:10.1002/ana.21876

6. Mathers CD, Loncar D. Projections of global mortality and burden of disease from 2002 to 2030. PLoS Med (2006) 3(11):e442. doi:10.1371/journal. pmed.0030442

7. Haring RS, Canner JK, Asemota AO, George BP, Selvarajah S, Haider AH, et al. Trends in incidence and severity of sports-related traumatic brain injury (TBI) in the emergency department, 2006-2011. Brain Injury (2015) 29(7-8):989-92. doi:10.3109/02699052.2015.1033014

8. Helmick KM, Spells CA, Malik SZ, Davies CA, Marion DW, Hinds SR. Traumatic brain injury in the US military: epidemiology and key clinical and research programs. Brain Imaging Behav (2015) 9(3):358-66. doi:10.1007/ s11682-015-9399-z

9. Brandel MG, Hirshman BR, McCutcheon BA, Tringale K, Carroll K, Richtand NM, et al. The association between psychiatric comorbidities and outcomes for inpatients with traumatic brain injury. J Neurotrauma (2017) 34(5):1005-16. doi:10.1089/neu.2016.4504

10. Arciniegas DB. Addressing neuropsychiatric disturbances during rehabilitation after traumatic brain injury: current and future methods. Dialogues Clin Neurosci (2011) 13(3):325-45 mechanisms to the development of neuropsychiatric symptoms will be elucidated. Future efforts should focus on further characterizing and identifying pituitary damage after TBI using prospective analyses with precise neuroimaging. In addition, it is imperative to employ more animal models of head injury to uncover the mechanisms by which PHTH occurs. Last, a goal toward teasing out associations between TBI and PTSD should be set, with a specific emphasis on possible neuroendocrinemediated contributions.

\section{AUTHOR CONTRIBUTIONS}

AM and JM conceived and wrote the manuscript.

\section{ACKNOWLEDGMENTS}

I would like to sincerely thank my Master's thesis advisor, JM, for her support and guidance during this project (131). JM was supported by NIH-NINDS grant R01 NS073574 (JM) and NS102937 (JM). I would also like to thank Dr. Chris Dulla for providing me with valuable feedback. Last, I would like to thank Dr. Ron Lechan for his important advice.

\section{FUNDING}

JM was supported by NIH-NINDS grant R01 NS073574 (JM) and NS102937 (JM).

11. Dusick JR, Wang C, Cohan P, Swerdloff R, Kelly DF. Pathophysiology of hypopituitarism in the setting of brain injury. Pituitary (2012) 15(1):2-9. doi:10.1007/s11102-008-0130-6

12. Hellawell DJ, Taylor RT, Pentland B. Cognitive and psychosocial outcome following moderate or severe traumatic brain injury. Brain Injury (1999) 13(7):489-504. doi:10.1080/026990599121403

13. Kraus JF, McArthur DL. Epidemiologic aspects of brain injury. Neurol Clin (1996) 14(2):435-50. doi:10.1016/S0733-8619(05)70266-8

14. Levin HS, Gary HE Jr, Eisenberg HM, Ruff RM, Barth JT, Kreutzer J, et al. Neurobehavioral outcome 1 year after severe head injury. Experience of the Traumatic Coma Data Bank. J Neurosurg (1990) 73(5):699-709. doi:10.3171/ jns.1990.73.5.0699

15. Lorenzo M, Peino R, Castro AI, Lage M, Popovic V, Dieguez C, et al. Hypopituitarism and growth hormone deficiency in adult subjects after traumatic brain injury: who and when to test. Pituitary (2005) 8(3-4):233-7. doi:10.1007/s11102-006-6046-0

16. Rutland-Brown W, Langlois JA, Thomas KE, Xi YL. Incidence of traumatic brain injury in the United States, 2003. J Head Trauma Rehabil (2006) 21(6):544-8. doi:10.1097/00001199-200611000-00009

17. Ellis MJ, Leddy J, Willer B. Multi-disciplinary management of athletes with post-concussion syndrome: an evolving pathophysiological approach. Front Neurol (2016) 7:136. doi:10.3389/fneur.2016.00136

18. Organization WH. In: Organization WH, editor. The ICD-10 Classification of Mental and Behavioural Disorders: Clinical Descriptions and Diagnostic Guidelines. Geneva, Switzerland: Stylus Publishing, LLC (1995).

19. Fann JR, Katon WJ, Uomoto JM, Esselman PC. Psychiatric disorders and functional disability in outpatients with traumatic brain injuries. Am JPsychiatry (1995) 152(10):1493-9. doi:10.1176/ajp.152.10.1493

20. Koponen S, Taiminen T, Portin R, Himanen L, Isoniemi H, Heinonen H, et al. Axis I and II psychiatric disorders after traumatic brain injury: a 30-year follow-up study. Am J Psychiatry (2002) 159(8):1315-21. doi:10.1176/appi. ajp.159.8.1315

21. Majors JS, Brennan J, Holt GR. Management of high-velocity injuries of the head and neck. Facial Plast Surg Clin North Am (2017) 25(4):493-502. doi:10.1016/j.fsc.2017.06.003 
22. Okie S. Traumatic brain injury in the war zone. N Engl J Med (2005) 352(20): 2043-7. doi:10.1056/NEJMp058102

23. Mescher AL. Endocrine glands. Junqueira’s Basic Histology: Text \& Atlas. (Vol. 13), New York, NY: McGraw-Hill. Available from: http://accessmedicine. mhmedical.com.ezproxy.library.tufts.edu/content.aspx?bookid=574\&sectionid $=42524606$ (Accessed: March 20, 2017).

24. Cyran E. Hypophysenschädigung durch schädelbasisfraktur. Dtsch Med Wochenschr (1918) 44(45):1261.

25. Kelly DF, Gonzalo IT, Cohan P, Berman N, Swerdloff R, Wang C. Hypopituitarism following traumatic brain injury and aneurysmal subarachnoid hemorrhage: a preliminary report. J Neurosurg (2000) 93(5):743-52. doi:10.3171/jns.2000.93.5.0743

26. Lieberman SA, Oberoi AL, Gilkison CR, Masel BE, Urban RJ. Prevalence of neuroendocrine dysfunction in patients recovering from traumatic brain injury. J Clin Endocrinol Metab (2001) 86(6):2752-6. doi:10.1210/jcem. 86.6.7592

27. Agha A, Rogers B, Sherlock M, O’Kelly P, Tormey W, Phillips J, et al. Anterior pituitary dysfunction in survivors of traumatic brain injury. J Clin Endocrinol Metab (2004) 89(10):4929-36. doi:10.1210/jc.2004-0511

28. Bondanelli M, De Marinis L, Ambrosio MR, Monesi M, Valle D, Zatelli MC, et al. Occurrence of pituitary dysfunction following traumatic brain injury. J Neurotrauma (2004) 21(6):685-96. doi:10.1089/0897715041269713

29. Aimaretti G, Ambrosio MR, Di Somma C, Fusco A, Cannavo S, Gasperi M, et al. Traumatic brain injury and subarachnoid haemorrhage are conditions at high risk for hypopituitarism: screening study at 3 months after the brain injury. Clin Endocrinol (2004) 61(3):320-6. doi:10.1111/j.1365-2265.2004. 02094.x

30. Popovic V, Pekic S, Pavlovic D, Maric N, Jasovic-Gasic M, Djurovic B, et al. Hypopituitarism as a consequence of traumatic brain injury (TBI) and its possible relation with cognitive disabilities and mental distress. J Endocrinol Invest (2004) 27(11):1048-54. doi:10.1007/BF03345308

31. Leal-Cerro A, Flores JM, Rincon M, Murillo F, Pujol M, Garcia-Pesquera F, et al. Prevalence of hypopituitarism and growth hormone deficiency in adults long-term after severe traumatic brain injury. Clin Endocrinol (2005) 62(5):525-32. doi:10.1111/j.1365-2265.2005.02250.x

32. Abadi MR, Ghodsi M, Merazin M, Roozbeh H. Pituitary function impairment after moderate traumatic brain injury. Acta Med Iran (2011) 49(7): $438-41$.

33. Hannon MJ, Crowley RK, Behan LA, O'Sullivan EP, O’Brien MM, Sherlock M, et al. Acute glucocorticoid deficiency and diabetes insipidus are common after acute traumatic brain injury and predict mortality. JClin Endocrinol Metab (2013) 98(8):3229-37. doi:10.1210/jc.2013-1555

34. Giuliano S, Talarico S, Bruno L, Nicoletti FB, Ceccotti C, Belfiore A. Growth hormone deficiency and hypopituitarism in adults after complicated mild traumatic brain injury. Endocrine (2017) 58(1):115-23. doi:10.1007/ s12020-016-1183-3

35. KelestimurF, TanriverdiF, Atmaca H, Unluhizarci K, Selcuklu A, Casanueva FF. Boxing as a sport activity associated with isolated GH deficiency. J Endocrinol Invest (2004) 27(11):Rc28-32. doi:10.1007/bf03345299

36. Tanriverdi F, Unluhizarci K, Coksevim B, Selcuklu A, Casanueva FF, Kelestimur F. Kickboxing sport as a new cause of traumatic brain injurymediated hypopituitarism. Clin Endocrinol (2007) 66(3):360-6. doi:10.1111/ j.1365-2265.2006.02737.x

37. Tanriverdi F, Unluhizarci K, Kocyigit I, Tuna IS, Karaca Z, Durak AC, et al. Brief communication: pituitary volume and function in competing and retired male boxers. Ann Intern Med (2008) 148(11):827-31. doi:10.7326/0003-4819-148-11-200806030-00005

38. Wilkinson CW, Pagulayan KF, Petrie EC, Mayer CL, Colasurdo EA, Shofer JB, et al. High prevalence of chronic pituitary and target-organ hormone abnormalities after blast-related mild traumatic brain injury. Front Neurol (2012) 3:11. doi:10.3389/fneur.2012.00011

39. Baxter D, Sharp DJ, Feeney C, Papadopoulou D, Ham TE, Jilka S, et al. Pituitary dysfunction after blast traumatic brain injury: the UK BIOSAP study. Ann Neurol (2013) 74(4):527-36. doi:10.1002/ana.23958

40. Ioachimescu AG, Hampstead BM, Moore A, Burgess E, Phillips LS. Growth hormone deficiency after mild combat-related traumatic brain injury. Pituitary (2015) 18(4):535-41. doi:10.1007/s11102-014-0606-5

41. Hoffman DM, O'Sullivan AJ, Baxter RC, Ho KK. Diagnosis of growthhormone deficiency in adults. Lancet (1994) 343(8905):1064-8. doi:10.1016/ S0140-6736(94)90181-3
42. Schneider HJ, Kreitschmann-Andermahr I, Ghigo E, Stalla GK, Agha A. Hypothalamopituitary dysfunction following traumatic brain injury and aneurysmal subarachnoid hemorrhage: a systematic review. JAMA (2007) 298(12):1429-38. doi:10.1001/jama.298.12.1429

43. Tanriverdi F, Schneider HJ, Aimaretti G, Masel BE, Casanueva FF, Kelestimur F. Pituitary dysfunction after traumatic brain injury: a clinical and pathophysiological approach. Endocr Rev (2015) 36(3):305-42. doi:10.1210/er. 2014-1065

44. Tan CL, Alavi SA, Baldeweg SE, Belli A, Carson A, Feeney C, et al. The screening and management of pituitary dysfunction following traumatic brain injury in adults: British Neurotrauma Group guidance. J Neurol Neurosurg Psychiatry (2017) 88(11):971-81. doi:10.1136/jnnp-2016-315500

45. Tölli A, Borg J, Bellander B-M, Johansson F, Höybye C. Pituitary function within the first year after traumatic brain injury or subarachnoid haemorrhage. J Endocrinol Invest (2017) 40(2):193-205. doi:10.1007/s40618-0160546-1

46. Javed Z, Qamar U, Sathyapalan T. Pituitary and/or hypothalamic dysfunction following moderate to severe traumatic brain injury: current perspectives. Ind J Endocrinol Metab (2015) 19(6):753-63. doi:10.4103/2230-8210. 167561

47. Behan LA, Phillips J, Thompson CJ, Agha A. Neuroendocrine disorders after traumatic brain injury. J Neurol Neurosurg Psychiatry (2008) 79(7):753-9. doi:10.1136/jnnp.2007.132837

48. Klose M, Feldt-Rasmussen U. Chronic endocrine consequences of traumatic brain injury - what is the evidence? Nat Rev Endocrinol (2018) 14:57-62. doi:10.1038/nrendo.2017.103

49. Klose M, Stochholm K, Janukonyte J, Lehman Christensen L, Frystyk J, Andersen M, et al. Prevalence of posttraumatic growth hormone deficiency is highly dependent on the diagnostic set-up: results from The Danish National Study on Posttraumatic Hypopituitarism. J Clin Endocrinol Metab (2014) 99(1):101-10. doi:10.1210/jc.2013-2397

50. Kokshoorn NE, Wassenaar MJ, Biermasz NR, Roelfsema F, Smit JW, Romijn JA, et al. Hypopituitarism following traumatic brain injury: prevalence is affected by the use of different dynamic tests and different normal values. Eur J Endocrinol (2010) 162(1):11-8. doi:10.1530/eje-09-0601

51. van Aken MO, Pereira AM, Biermasz NR, van Thiel SW, Hoftijzer HC, Smit JW, et al. Quality of life in patients after long-term biochemical cure of Cushing's disease. J Clin Endocrinol Metab (2005) 90(6):3279-86. doi:10.1210/jc.2004-1375

52. Simpson H, Savine R, Sonksen P, Bengtsson BA, Carlsson L, Christiansen JS, et al. Growth hormone replacement therapy for adults: into the new millennium. Growth Horm IGF Res (2002) 12(1):1-33. doi:10.1054/ghir. 2001.0263

53. McGauley GA. Quality of life assessment before and after growth hormone treatment in adults with growth hormone deficiency. Acta Paediatr Scand Suppl (1989) 356:70-2; discussion 3-4. doi:10.1111/j.1651-2227.1989. tb11249.x

54. McGauley GA, Cuneo RC, Salomon F, Sonksen PH. Psychological well-being before and after growth hormone treatment in adults with growth hormone deficiency. Horm Res (1990) 33(Suppl 4):52-4. doi:10.1159/000181584

55. Rosen T, Wiren L, Wilhelmsen L, Wiklund I, Bengtsson BA. Decreased psychological well-being in adult patients with growth hormone deficiency. Clin Endocrinol (1994) 40(1):111-6. doi:10.1111/j.1365-2265.1994.tb02452.x

56. Bavisetty S, Bavisetty S, McArthur DL, Dusick JR, Wang C, Cohan P, et al. Chronic hypopituitarism after traumatic brain injury: risk assessment and relationship to outcome. Neurosurgery (2008) 62(5):1080-93; discussion 93-4. doi:10.1227/01.neu.0000325870.60129.6a

57. Kelly DF, McArthur DL, Levin H, Swimmer S, Dusick JR, Cohan P, et al. Neurobehavioral and quality of life changes associated with growth hormone insufficiency after complicated mild, moderate, or severe traumatic brain injury. J Neurotrauma (2006) 23(6):928-42. doi:10.1089/neu.2006.23.928

58. Leon-Carrion J, Leal-Cerro A, Cabezas FM, Atutxa AM, Gomez SG, Cordero $\mathrm{JM}$, et al. Cognitive deterioration due to GH deficiency in patients with traumatic brain injury: a preliminary report. Brain Injury (2007) 21(8):871-5. doi:10.1080/02699050701484849

59. Ojo JO, Greenberg MB, Leary P, Mouzon B, Bachmeier C, Mullan M, et al. Neurobehavioral, neuropathological and biochemical profiles in a novel mouse model of co-morbid post-traumatic stress disorder and mild traumatic brain injury. Front Behav Neurosci (2014) 8:213. doi:10.3389/ fnbeh.2014.00213 
60. Undurti A, Colasurdo EA, Sikkema CL, Schultz JS, Peskind ER, Pagulayan KF, et al. Chronic hypopituitarism associated with increased postconcussive symptoms is prevalent after blast-induced mild traumatic brain injury. Front Neurol (2018) 9:72. doi:10.3389/fneur.2018.00072

61. Zoladz PR, Diamond DM. Current status on behavioral and biological markers of PTSD: a search for clarity in a conflicting literature. Neurosci Biobehav Rev (2013) 37(5):860-95. doi:10.1016/j.neubiorev.2013.03.024

62. Chiolero R, Berger M. Endocrine response to brain injury. New Horiz (1994) 2(4):432-42.

63. Simsek T, Simsek HU, Canturk NZ. Response to trauma and metabolic changes: posttraumatic metabolism. Ulus Cerrahi Derg (2014) 30(3):153-9. doi:10.5152/ucd.2014.2653

64. Desborough JP. The stress response to trauma and surgery. Br J Anaesth (2000) 85(1):109-17. doi:10.1093/bja/85.1.109

65. Vanhorebeek I, Langouche L, Van den Berghe G. Endocrine aspects of acute and prolonged critical illness. Nat Clin Pract Endocrinol Metab (2006) 2(1):20-31. doi:10.1038/ncpendmet0071

66. Van den Berghe G. Novel insights into the neuroendocrinology of critical illness. Eur J Endocrinol (2000) 143(1):1-13. doi:10.1530/eje.0.1430001

67. Van den Berghe GH. Acute and prolonged critical illness are two distinct neuroendocrine paradigms. Verh K Acad Geneeskd Belg (1998) 60(6):487-518; discussion 20

68. Van den Berghe G, Wouters P, Weekers F, Mohan S, Baxter RC, Veldhuis JD, et al. Reactivation of pituitary hormone release and metabolic improvement by infusion of growth hormone-releasing peptide and thyrotropin-releasing hormone in patients with protracted critical illness. J Clin Endocrinol Metab (1999) 84(4):1311-23. doi:10.1210/jcem.84.4.5636

69. Petersen SR, Jeevanandam M, Harrington T. Is the metabolic response to injury different with or without severe head injury? Significance of plasma glutamine levels. J Trauma (1993) 34(5):653-60; discussion 660-1. doi:10.1097/00005373-199305000-00007

70. Barton RN, Stoner HB, Watson SM. Relationships among plasma cortisol, adrenocorticotrophin, and severity of injury in recently injured patients. J Trauma (1987) 27(4):384-92. doi:10.1097/00005373-198704000-00007

71. Taylor AN, Rahman SU, Sanders NC, Tio DL, Prolo P, Sutton RL. Injury severity differentially affects short- and long-term neuroendocrine outcomes of traumatic brain injury. J Neurotrauma (2008) 25(4):311-23. doi:10.1089/ neu.2007.0486

72. Taylor AN, Rahman SU, Tio DL, Sanders MJ, Bando JK, Truong AH, et al. Lasting neuroendocrine-immune effects of traumatic brain injury in rats. J Neurotrauma (2006) 23(12):1802-13. doi:10.1089/neu.2006.23.1802

73. Taylor AN, Tio DL, Sutton RL. Restoration of neuroendocrine stress response by glucocorticoid receptor or GABA(A) receptor antagonists after experimental traumatic brain injury. J Neurotrauma (2013) 30(14):1250-6. doi:10.1089/neu.2012.2847

74. Maiya B, Newcombe V, Nortje J, Bradley P, Bernard F, Chatfield D, et al. Magnetic resonance imaging changes in the pituitary gland following acute traumatic brain injury. Intensive Care Med (2008) 34(3):468-75. doi:10.1007/ s00134-007-0902-X

75. Bistritzer T, Theodor R, Inbar D, Cohen BE, Sack J. Anterior hypopituitarism due to fracture of the sella turcica. Am J Dis Child (1981) 135(10): 966-8.

76. Asa SL, Kovacs K, Bilbao JM. The pars tuberalis of the human pituitary. A histologic, immunohistochemical, ultrastructural and immunoelectron microscopic analysis. Virchows Arch A Pathol Anat Histopathol (1983) 399(1):49-59. doi:10.1007/BF00666218

77. Larkin S, Ansorge O. Development and microscopic anatomy of the pituitary gland. In: De Groot LJ, Chrousos G, Dungan K, Feingold KR, Grossman A, Hershman JM, et al., editors. Endotext. South Dartmouth, MA: MDText.com, Inc. (2000).

78. Simmons AN, Matthews SC. Neural circuitry of PTSD with or without mild traumatic brain injury: a meta-analysis. Neuropharmacology (2012) 62(2):598-606. doi:10.1016/j.neuropharm.2011.03.016

79. Tan H, Yang W, Wu C, Liu B, Lu H, Wang H, et al. Assessment of the role of intracranial hypertension and stress on hippocampal cell apoptosis and hypothalamic-pituitary dysfunction after TBI. Sci Rep (2017) 7(1):3805. doi:10.1038/s41598-017-04008-w

80. Tumer N, Svetlov S, Whidden M, Kirichenko N, Prima V, Erdos B, et al. Overpressure blast-wave induced brain injury elevates oxidative stress in the hypothalamus and catecholamine biosynthesis in the rat adrenal medulla. Neurosci Lett (2013) 544:62-7. doi:10.1016/j.neulet.2013.03.042

81. Guaraldi F, Grottoli S, Arvat E, Ghigo E. Hypothalamic-pituitary autoimmunity and traumatic brain injury. J Clin Med (2015) 4(5):1025-35. doi:10.3390/ jcm4051025

82. Daniel PM, Prichard MM, Treip CS. Traumatic infarction of the anterior lobe of the pituitary gland. Lancet (1959) 2(7109):927-31. doi:10.1016/ S0140-6736(59)91583-1

83. Gorczyca W, Hardy J. Arterial supply of the human anterior pituitary gland. Neurosurgery (1987) 20(3):369-78. doi:10.1227/00006123-198703000-00003

84. Nussey S, Whitehead S. The pituitary gland. Endocrinology: An Integrated Approach. BIOS Scientific Publishers Limited (2001). Available from: https:// www.ncbi.nlm.nih.gov/books/NBK27/ (Accessed: November 22, 2017).

85. Kontogeorgos G, Stefaneanu L, Kovacs K, Horvath E. Hypophysis A2 - Mai, Jürgen K. 3rd ed. In: Paxinos G, editor. The Human Nervous System. (Chap. 17), San Diego: Academic Press (2012). p. 584-93.

86. Stieg MR. Advances in understanding hypopituitarism. F1000Res (2017) 6:178. doi:10.12688/f1000research.9436.1

87. Melmed S. The Pituitary. 4th ed. London, UK: Academic Press Is an Imprint of Elsevier (2017).

88. Kelestimur F, Jonsson P, Molvalilar S, Gomez JM, Auernhammer CJ, Colak R, et al. Sheehan's syndrome: baseline characteristics and effect of 2 years of growth hormone replacement therapy in 91 patients in KIMS - Pfizer International Metabolic Database. Eur J Endocrinol (2005) 152(4):581-7. doi:10.1530/eje.1.01881

89. Ceballos R. Pituitary changes in head trauma (analysis of 102 consecutive cases of head injury). Ala J Med Sci (1966) 3(2):185-98.

90. Kornblum RN, Fisher RS. Pituitary lesions in craniocerebral injuries. Arch Pathol (1969) 88(3):242-8.

91. Benvenga S, Campenni A, Ruggeri RM, Trimarchi F. Clinical review 113: hypopituitarism secondary to head trauma. J Clin Endocrinol Metab (2000) 85(4):1353-61. doi:10.1210/jcem.85.4.6506

92. Salehi F, Kovacs K, Scheithauer BW, Pfeifer EA, Cusimano M. Histologic study of the human pituitary gland in acute traumatic brain injury. Brain Injury (2007) 21(6):651-6. doi:10.1080/02699050701426956

93. Schneider HJ, Samann PG, Schneider M, Croce CG, Corneli G, Sievers C, et al. Pituitary imaging abnormalities in patients with and without hypopituitarism after traumatic brain injury. J Endocrinol Invest (2007) 30(4):Rc9-12. doi:10.1007/bf03346291

94. De Marinis L, Bonadonna S, Bianchi A, Maira G, Giustina A. Primary empty sella. J Clin Endocrinol Metab (2005) 90(9):5471-7. doi:10.1210/jc. 2005-0288

95. Zheng P, He B, Tong WS. Decrease in pituitary apparent diffusion coefficient in normal appearing brain correlates with hypopituitarism following traumatic brain injury. J Endocrinol Invest (2014) 37(3):309-12. doi:10.1007/ s40618-014-0059-8

96. Greco T, Hovda D, Prins M. The effects of repeat traumatic brain injury on the pituitary in adolescent rats. J Neurotrauma (2013) 30(23):1983-90 doi:10.1089/neu.2013.2990

97. Ozdemir D, Baykara B, Aksu I, Kiray M, Sisman AR, Cetin F, et al. Relationship between circulating IGF-1 levels and traumatic brain injury-induced hippocampal damage and cognitive dysfunction in immature rats. Neurosci Lett (2012) 507(1):84-9. doi:10.1016/j.neulet.2011.11.059

98. Osterstock G, El Yandouzi T, Romano N, Carmignac D, Langlet F, Coutry N, et al. Sustained alterations of hypothalamic tanycytes during posttraumatic hypopituitarism in male mice. Endocrinology (2014) 155(5):1887-98. doi:10.1210/en.2013-1336

99. Mullier A, Bouret SG, Prevot V, Dehouck B. Differential distribution of tight junction proteins suggests a role for tanycytes in blood-hypothalamus barrier regulation in the adult mouse brain. J Comp Neurol (2010) 518(7):943-62. doi: $10.1002 / \mathrm{cne} .22273$

100. Laskowitz DT, Thekdi AD, Thekdi SD, Han SK, Myers JK, Pizzo SV, et al. Downregulation of microglial activation by apolipoprotein $\mathrm{E}$ and apoE-mimetic peptides. Exp Neurol (2001) 167(1):74-85. doi:10.1006/exnr 2001.7541

101. Tanriverdi F, Taheri S, Ulutabanca H, Caglayan AO, Ozkul Y, Dundar M, et al. Apolipoprotein E3/E3 genotype decreases the risk of pituitary dysfunction after traumatic brain injury due to various causes: preliminary data. J Neurotrauma (2008) 25(9):1071-7. doi:10.1089/neu.2007.0456 
102. Kasturi BS, Stein DG. Traumatic brain injury causes long-term reduction in serum growth hormone and persistent astrocytosis in the cortico-hypothalamo-pituitary axis of adult male rats. J Neurotrauma (2009) 26(8):1315-24. doi:10.1089/neu.2008-0751

103. Tanriverdi F, De Bellis A, Bizzarro A, Sinisi AA, Bellastella G, Pane E, et al. Antipituitary antibodies after traumatic brain injury: is head trauma-induced pituitary dysfunction associated with autoimmunity? Eur J Endocrinol (2008) 159(1):7-13. doi:10.1530/eje-08-0050

104. Tanriverdi F, De Bellis A, Ulutabanca H, Bizzarro A, Sinisi AA, Bellastella G, et al. A five year prospective investigation of anterior pituitary function after traumatic brain injury: is hypopituitarism long-term after head trauma associated with autoimmunity? J Neurotrauma (2013) 30(16):1426-33. doi:10.1089/neu.2012.2752

105. Tanriverdi F, De Bellis A, Battaglia M, Bellastella G, Bizzarro A, Sinisi AA, et al. Investigation of antihypothalamus and antipituitary antibodies in amateur boxers: is chronic repetitive head trauma-induced pituitary dysfunction associated with autoimmunity? Eur J Endocrinol (2010) 162(5):861-7. doi:10.1530/eje-09-1024

106. Dulla CG, Coulter DA, Ziburkus J. From molecular circuit dysfunction to disease: case studies in epilepsy, traumatic brain injury, and Alzheimer's disease. Neuroscientist (2016) 22(3):295-312. doi:10.1177/ 1073858415585108

107. Povlishock JT, Erb DE, Astruc J. Axonal response to traumatic brain injury: reactive axonal change, deafferentation, and neuroplasticity. J Neurotrauma (1992) 9(Suppl 1):S189-200.

108. Johnson VE, Stewart W, Smith DH. Axonal pathology in traumatic brain injury. Exp Neurol (2013) 246:35-43. doi:10.1016/j.expneurol.2012.01.013

109. Bazarian JJ, Zhong J, Blyth B, Zhu T, Kavcic V, Peterson D. Diffusion tensor imaging detects clinically important axonal damage after mild traumatic brain injury: a pilot study. J Neurotrauma (2007) 24(9):1447-59. doi:10.1089/ neu.2007.0241

110. Xiao H, Yang Y, Xi JH, Chen ZQ. Structural and functional connectivity in traumatic brain injury. Neural Regen Res (2015) 10(12):2062-71. doi:10.4103/ 1673-5374.172328

111. Mantini D, Vanduffel W. Emerging roles of the brain's default network. Neuroscientist (2013) 19(1):76-87. doi:10.1177/1073858412446202

112. Bonnelle V, Ham TE, Leech R, Kinnunen KM, Mehta MA, Greenwood RJ, et al. Salience network integrity predicts default mode network function after traumatic brain injury. Proc Natl Acad Sci U S A (2012) 109(12):4690-5. doi:10.1073/pnas.1113455109

113. Weissman DH, Roberts KC, Visscher KM, Woldorff MG. The neural bases of momentary lapses in attention. Nat Neurosci (2006) 9(7):971-8. doi:10.1038/ $\mathrm{nn} 1727$

114. Zhou Y, Milham MP, Lui YW, Miles L, Reaume J, Sodickson DK, et al. Default-mode network disruption in mild traumatic brain injury. Radiology (2012) 265(3):882-92. doi:10.1148/radiol.12120748

115. McAllister TW. Neurobehavioral sequelae of traumatic brain injury: evaluation and management. World Psychiatry (2008) 7(1):3-10. doi:10.1002/ j.2051-5545.2008.tb00139.x

116. McAllister TW. Neurobiological consequences of traumatic brain injury. Dialogues Clin Neurosci (2011) 13(3):287-300.

117. Holmes A, Wellman CL. Stress-induced prefrontal reorganization and executive dysfunction in rodents. Neurosci Biobehav Rev (2009) 33(6):773-83. doi:10.1016/j.neubiorev.2008.11.005

118. Rauch SL, Shin LM, Phelps EA. Neurocircuitry models of posttraumatic stress disorder and extinction: human neuroimaging research - past, present, and future. Biol Psychiatry (2006) 60(4):376-82. doi:10.1016/j. biopsych.2006.06.004
119. Bryant R. Post-traumatic stress disorder vs traumatic brain injury. Dialogues Clin Neurosci (2011) 13(3):251-62.

120. Elder GA, Dorr NP, De Gasperi R, Gama Sosa MA, Shaughness MC, Maudlin-Jeronimo E, et al. Blast exposure induces post-traumatic stress disorder-related traits in a rat model of mild traumatic brain injury. J Neurotrauma (2012) 29(16):2564-75. doi:10.1089/neu.2012.2510

121. Gil S, Caspi Y, Ben-Ari IZ, Koren D, Klein E. Does memory of a traumatic event increase the risk for posttraumatic stress disorder in patients with traumatic brain injury? A prospective study. Am J Psychiatry (2005) 162(5):963-9. doi:10.1176/appi.ajp.162.5.963

122. Cahill L, Prins B, Weber M, McGaugh JL. Beta-adrenergic activation and memory for emotional events. Nature (1994) 371(6499):702-4. doi:10.1038/371702a0

123. Lonergan MH, Olivera-Figueroa LA, Pitman RK, Brunet A. Propranolol's effects on the consolidation and reconsolidation of long-term emotional memory in healthy participants: a meta-analysis. J Psychiatry Neurosci (2013) 38(4):222-31. doi:10.1503/jpn.120111

124. Brunet A, Orr SP, Tremblay J, Robertson K, Nader K, Pitman RK. Effect of post-retrieval propranolol on psychophysiologic responding during subsequent script-driven traumatic imagery in post-traumatic stress disorder. $J$ Psychiatr Res (2008) 42(6):503-6. doi:10.1016/j.jpsychires.2007.05.006

125. Brunet A, Poundja J, Tremblay J, Bui E, Thomas E, Orr SP, et al. Trauma reactivation under the influence of propranolol decreases posttraumatic stress symptoms and disorder: 3 open-label trials. J Clin Psychopharmacol (2011) 31(4):547-50. doi:10.1097/JCP.0b013e318222f360

126. Bryant RA. Posttraumatic stress disorder and mild brain injury: controversies, causes and consequences. J Clin Exp Neuropsychol (2001) 23(6):718-28. doi:10.1076/jcen.23.6.718.1024

127. Hoge CW, McGurk D, Thomas JL, Cox AL, Engel CC, Castro CA. Mild traumatic brain injury in U.S. Soldiers returning from Iraq. $N$ Engl J Med (2008) 358(5):453-63. doi:10.1056/NEJMoa072972

128. Stark EA, Parsons CE, Van Hartevelt TJ, Charquero-Ballester M, McManners $\mathrm{H}$, Ehlers A, et al. Post-traumatic stress influences the brain even in the absence of symptoms: a systematic, quantitative meta-analysis of neuroimaging studies. Neurosci Biobehav Rev (2015) 56:207-21. doi:10.1016/j.neubiorev. 2015.07.007

129. Mason JW, Giller EL, Kosten TR, Ostroff RB, Podd L. Urinary free-cortisol levels in posttraumatic stress disorder patients. J Nerv Ment Dis (1986) 174(3):145-9. doi:10.1097/00005053-198603000-00003

130. Resnick HS, Yehuda R, Pitman RK, Foy DW. Effect of previous trauma on acute plasma cortisol level following rape. Am JPsychiatry (1995) 152(11):1675-7. doi:10.1176/ajp.152.11.1675

131. Molaie A. Neuroendocrine Abnormalities Following Traumatic Brain Injury: An Important Contributor to Neuropsychiatric Sequelae. Boston: Tufts University Database (2016).

Conflict of Interest Statement: The authors declare that the research was conducted in the absence of any commercial or financial relationships that could be construed as a potential conflict of interest.

The reviewer BN declared a shared affiliation, with no collaboration, with the author JM to the handling Editor.

Copyright $\odot 2018$ Molaie and Maguire. This is an open-access article distributed under the terms of the Creative Commons Attribution License (CC BY). The use, distribution or reproduction in other forums is permitted, provided the original author(s) and the copyright owner are credited and that the original publication in this journal is cited, in accordance with accepted academic practice. No use, distribution or reproduction is permitted which does not comply with these terms. 